\title{
TRANSMYOCARDIAL LASER REVASCULARIZATION: THREE SEQUENTIAL AUTOPSY CASES
}

\author{
J. E. Sigel, MD, C. M. Abramovich, MD, B. W. Lytle, MD, and N. B. Ratliff, MD, Cleveland, Ohio
}

Transmyocardial laser revascularization (TMLR) is an investigational procedure designed to allow perfusion of ischemic myocardium with oxygenated blood directly from the left ventricle (LV) through microscopic channels created with a carbon dioxide laser. TMLR is currently being offered to patients who are unsuitable candidates for coronary bypass operations or percutaneous transluminal coronary angioplasty and who have severe angina refractory to medical treatment.

In 1965 , Sen and associates ${ }^{1}$ discovered that the reptilian myocardium is perfused by channels that radiate from a single ventricle into the surrounding muscle with only a thin shell of myocardium being supplied by coronary arteries. Sen's group attempted to reproduce the reptilian model of myocardial perfusion by performing transmyocardial acupuncture.

Today, transmyocardial acupuncture has been replaced by the development of high-energy carbon dioxide lasers that create transmyocardial channels in beating hearts without cardiopulmonary bypass (TMLR).

Clinical studies of TMLR have reported decreased angina, increased treadmill tolerance, and an increase in relative subendocardial perfusion of laser-treated areas as measured by nuclear studies and positron emission tomographic scans 3,6 , and 12 months after the operations. ${ }^{2-4}$ Recently, a large 1:1 randomized prospective clinical study comparing TMLR to continued medical management in patients with symptomatic, end-stage coronary artery disease reported improved event-free survival, angina class, and quality of life after TMLR.*

Patients and methods. We performed three autopsies at the Cleveland Clinic Foundation on patients who had

From the Departments of Anatomic Pathology and Surgery, The Cleveland Clinic Foundation, Cleveland, Ohio.

Received for publication Oct. 27, 1997; accepted for publication Jan. 5, 1998.

* March RJ, Aranki A, Berman DS, Boyce SW, Cohn L, Cooley DA, et al. Improved event free survival following transmyocardial laser revascularization versus medical management in patients with unreconstructable coronary artery disease. Submitted for publication. had TMLR with a high-energy carbon dioxide laser (The Heart Laser, PLC Medical Systems, Milford, Mass.). Each patient had had severe angina. Preoperative studies identified severe diffuse coronary artery atherosclerosis and LV systolic dysfunction. The patients were not candidates for conventional revascularization procedures because of diffuse distal coronary artery atherosclerosis.

The operative procedure used was similar to the procedure described in previous studies. ${ }^{2,4,5}$ Twenty-five to thirty channels were created per patient in an area where ischemic or hibernating myocardium had been discovered with perioperative thallium or positron emission tomographic studies (or both). Bypass grafting was not performed in association with TMLR.

The patients died less than 24 hours, 10 days, and 3 weeks after the operation, respectively, allowing the progression of healing within the laser channels to be studied.

Causes of death included a perioperative myocardial infarct in the patient who died suddenly; sepsis, congestive heart failure, and chronic renal failure in the patient who died 10 days after the operation; and sepsis, adult respiratory distress syndrome, and multiorgan system failure in the patient who died 3 weeks after the operation.

In each case, the laser channels were identified at autopsy as small punctate depressions on the epicardial surface of the LV. Multiple blocks were taken both perpendicular and parallel to these depressions. The blocks were fixed in formalin, embedded in paraffin, step-sectioned, and stained with hematoxylin-eosin.

Results. In each case, multiple laser channels that penetrated the entire thickness of the LV from the epicardium through the endocardium were identified microscopically. In addition, each case had diffuse fibrosis of the LV.

Address for reprints: Norman B. Ratliff, MD, Cleveland Clinic Foundation, Department of Anatomic Pathology (L25), 9500 Euclid Ave., Cleveland, OH 44195.

J Thorac Cardiovasc Surg 1998;115:1381-5

Copyright $(\odot) 1998$ by Mosby, Inc.

$0022-5223 / 98 \$ 5.00+0 \quad \mathbf{1 2 / 5 4 / 8 8 6 7 9}$ 


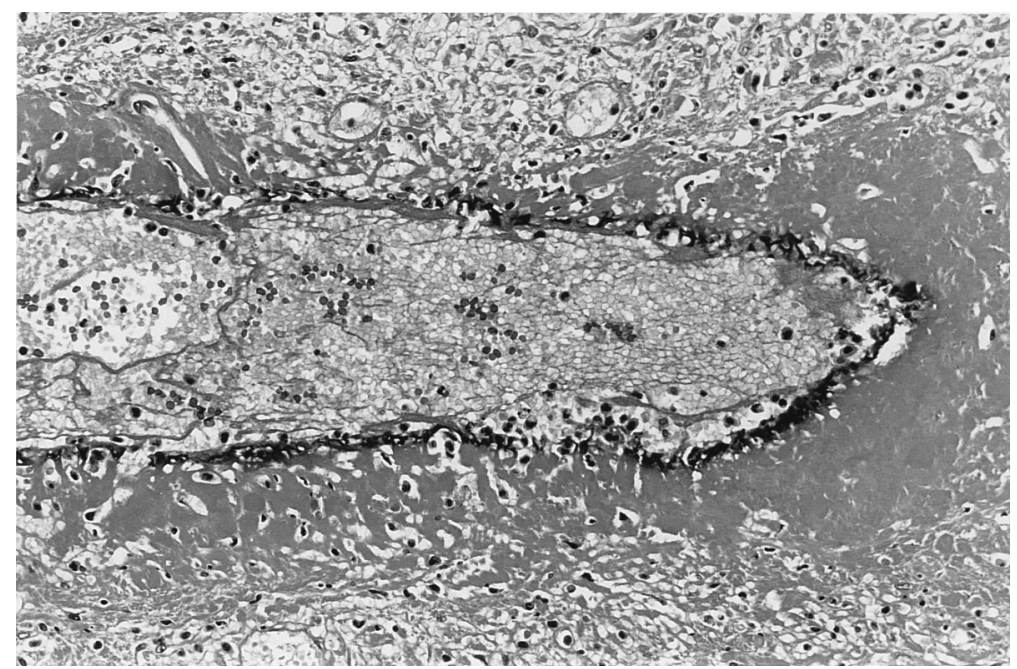

Fig. 1. This laser channel from the acute postoperative phase demonstrates sharp, well-demarcated borders surrounded by a thin zone of thermal-induced char and coagulated protein. The lumen of the channel is filled with coagulated protein, blood, and acute inflammatory cells.

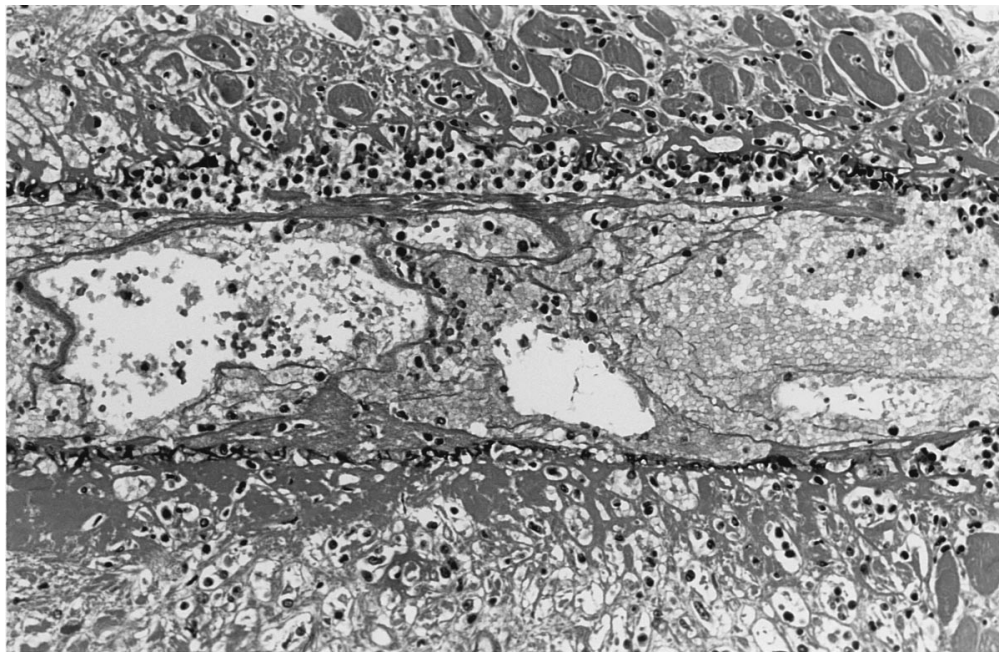

Fig. 2. This laser channel from the acute postoperative phase demonstrates a zone of acute inflammation and necrotic myocytes in the immediately adjacent myocardium. As in Fig. 1, the lumen is filled with coagulated protein, blood, and acute inflammatory cells.

In the patient who died suddenly, the channels were bordered by a thin zone of thermal-induced char and were filled with coagulated protein, blood, and acute inflammatory cells. The inflammation extended into the immediately adjacent myocardium (Figs. 1 and 2). Collateral damage was restricted to coagulative necrosis of individual myocytes adjacent to the laser channels and to a narrow cuff of subepicardial myocytes surrounding the beginning of a single channel (Fig. 3). In addition, a recent subendocardial myocardial infarct of the posterolateral LV was identified.

In the patient who died 10 days after the operation, the laser channels continued to have well-demarcated bor- ders. The zone of thermal-induced char was reduced. The protein coagulum was replaced by fibroblasts, macrophages, multinucleated foreign-body giant cells, and small blood vessels (Fig. 4). Channels coursing through areas of myocardial fibrosis showed a delay in progression with retention of char and protein coagulum. A laser-disrupted atherosclerotic vessel, as well as calcific emboli in small intramyocardial vessels, was identified representing a potential complication of TMLR (Fig. 5). Exuberant granulation tissue was present in the epicardium.

In the patient who died 3 weeks after the operation, well-demarcated transmural channels were identified filled with granulation tissue and fibrosis (Fig. 6). 


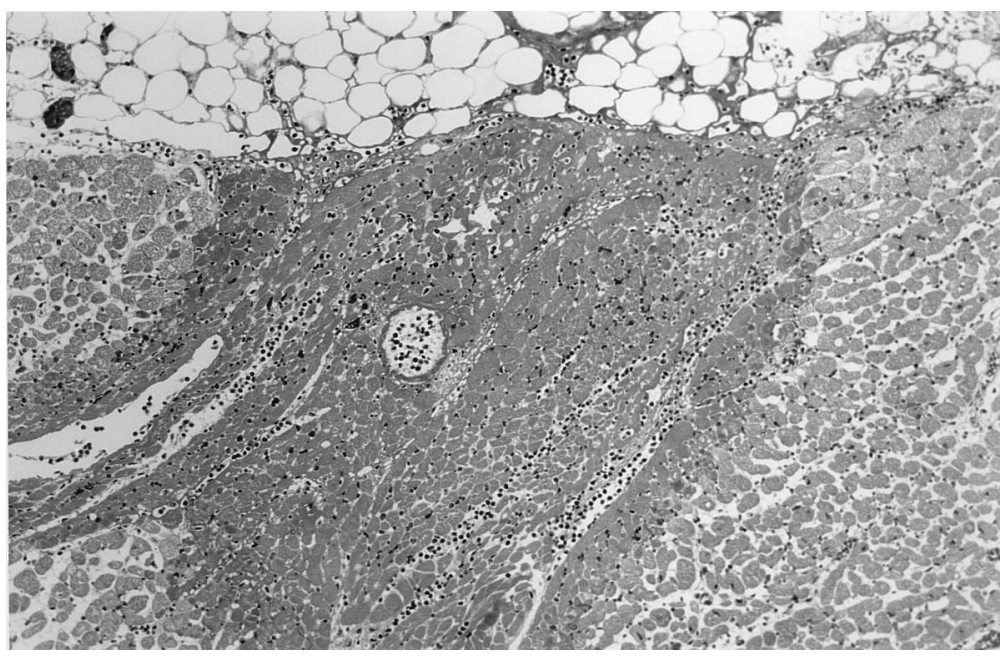

Fig. 3. Collateral damage in the acute postoperative phase included a narrow cuff of necrotic subepicardial myocytes surrounding the entrance of a single laser channel into the myocardium.

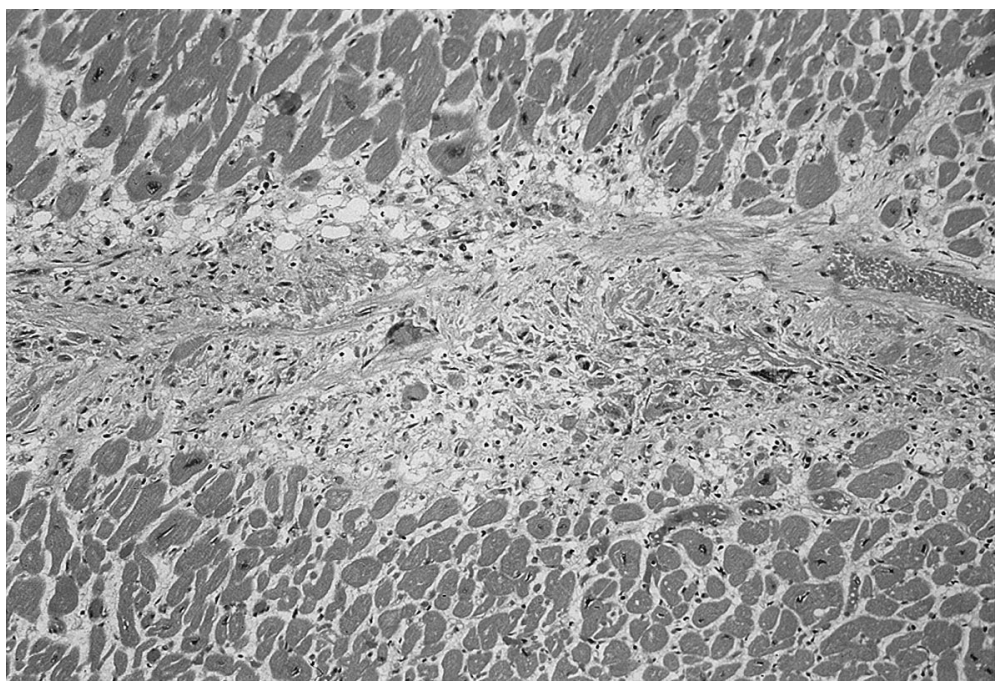

Fig. 4. This laser channel from 10 days after the operation demonstrates sharp, well-demarcated borders. The lumen of the channel is filled with fibroblasts, macrophages, multinucleated foreign-body giant cells, and small blood vessels.

Several channels contained an intense foreign-body giant cell response. The giant cells were increased in number and size as compared with those in the previous case. Visible material, some polarizable and some pigmented, was identified in the cytoplasm of several giant cells. Similar to the previous case, thermal-induced char and protein coagulum persisted in areas of myocardial fibrosis.

Discussion. In these three autopsies, it was clear that the laser channels were not patent. Instead, the channels showed evidence of wound healing with fibrosis. This finding raises the question of whether this might be a general finding after TMLR or whether it is peculiar to those patients who died.
A randomized study has produced evidence that patients undergoing TMLR have improved symptoms and improved myocardial perfusion as judged by radionuclide scans when compared with patients managed medically.* How can this be reconciled with our findings of lack of perfusion through the laser channels? One possible explanation is that the patients undergoing autopsies were different from long-term

*March RJ, Aranki A, Berman DS, Boyce SW, Cohn L, Cooley DA, et al. Improved event free survival following transmyocardial laser revascularization versus medical management in patients with unreconstructable coronary artery disease. Submitted for publication. 


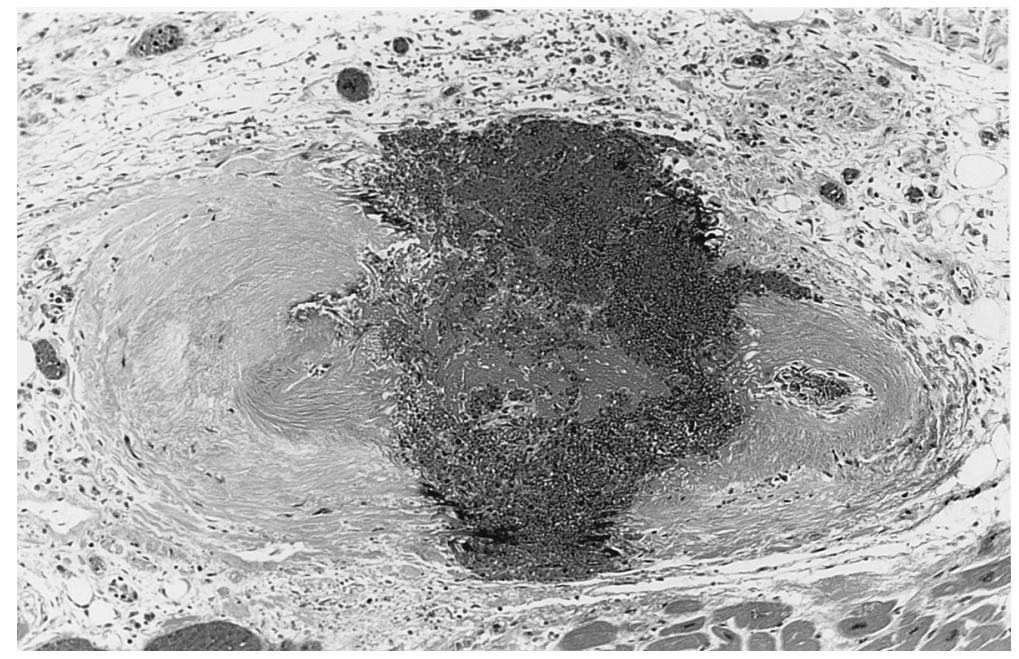

Fig. 5. Ten days after the operation, this small atherosclerotic intramyocardial coronary artery has been disrupted by the laser. A dark-colored necrotic laser tract traversing the vessel from top to bottom is evident.

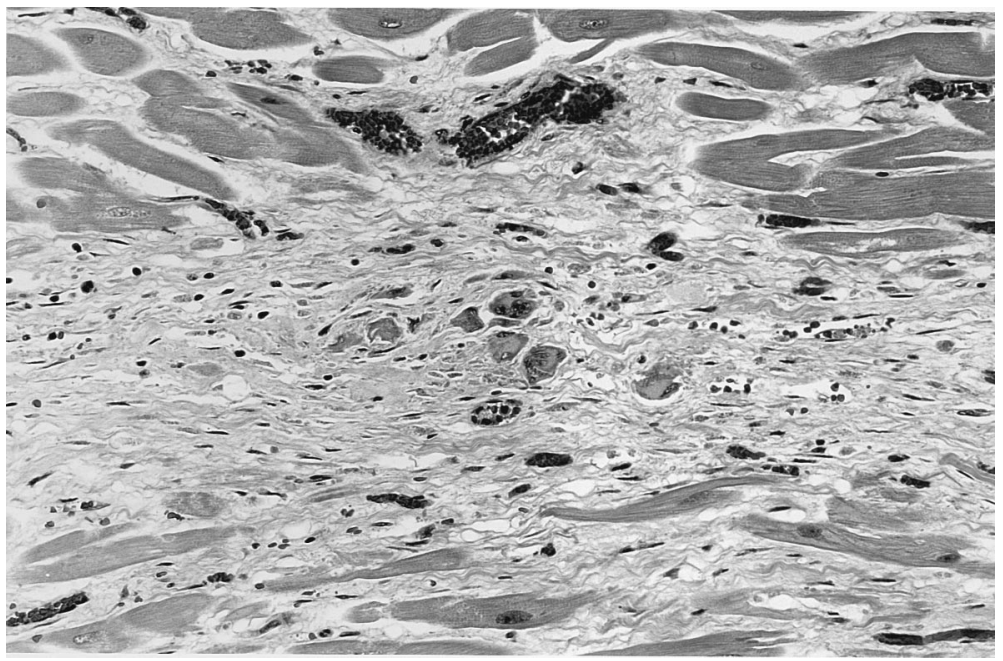

Fig. 6. The lumen of this well-demarcated laser channel from an autopsy done 3 weeks after the operation is filled with granulation tissue, fibrosis, and multinucleated foreign-body giant cells.

survivors of TMLR and, in fact, died because of channel occlusion. Another possibility is that the occluded channels may reopen later, and the third is that the channels remain occluded but that TMLR stimulates angiogenesis. It has been observed that the symptom response and improvements in radionuclide scans are not immediate but improved with time up to 6 months after TMLR.*

*March RJ, Aranki A, Berman DS, Boyce SW, Cohn L, Cooley DA, et al. Improved event free survival following transmyocardial laser revascularization versus medical management in patients with unreconstructable coronary artery disease. Submitted for publication.
It appears that patients do not exhibit consistent improvement in myocardial perfusion immediately after TMLR. Therefore particular care must be taken in the postoperative management of these incompletely revascularized patients to compensate for the lack of immediate improvement in myocardial perfusion.

In conclusion, the absence of patent channels in these three autopsies performed at different postoperative intervals fails to support the hypothesis that laser-induced transmyocardial channels would carry blood directly from the LV into the surrounding myocardium. At this point, the mechanism of the clinical improvement generated by TMLR remains unknown. 


\section{REFERENCES}

1. Sen PK, Udwadia TE, Kinare SG, Parulkar GB. Transmyocardial acupuncture: a new approach to myocardial revascularization. J Thorac Cardiovasc Surg 1965;50:1819.

2. Cooley DA, Frazier OH, Kadipasaoglu KA, Lindenmeir MH, Pehlivanoglu S, Kolff JW, et al. Transmyocardial laser revascularization: clinical experience with twelve-month follow-up. J Thorac Cardiovasc Surg 1996;111:791-7.

3. Frazier OH, Cooley DA, Kadipasaoglu KA, Pehlivanoglu S, Lindenmeir M, Barasch E, et al. Transmyocardial laser revas- cularization: preliminary findings. Circulation 1995;92(Suppl): II58-65.

4. Horvath KA, Mannting F, Cummings N, Shernan SK, Cohn LH. Transmyocardial laser revascularization: operative techniques and clinical results at two years. J Thorac Cardiovasc Surg 1996;111:1047-53.

5. Horvath KA, Cohn LH, Cooley DA, Crew JR, Frazier OH, Griffith BP, et al. Transmyocardial laser revascularization: results of a multicenter trial with transmyocardial laser revassole therapy for end-stage coronary artery disease. $\mathrm{J}$ Thorac Cardiovasc Surg 1997;113:645-54. 